\title{
EE FY00 Report: Nanostructure Multilayer Materials for Capacitors
}

\author{
T. W. Barbee
}

October 26, 2000

U.S. Department of Energy

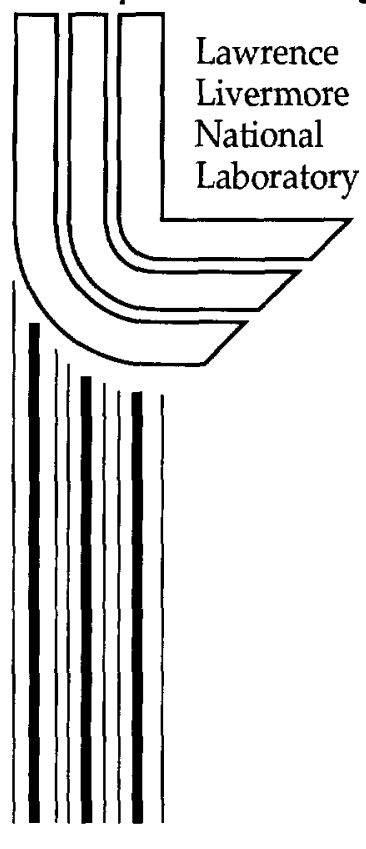




\section{DISCLAIMER}

This document was prepared as an account of work sponsored by an agency of the United States Government. Neither the United States Government nor the University of California nor any of their employees, makes any warranty, express or implied, or assumes any legal liability or responsibility for the accuracy, completeness, or usefulness of any information, apparatus, product, or process disclosed, or represents that its use would not infringe privately owned rights. Reference herein to any specific commercial product, process, or service by trade name, trademark, manufacturer, or otherwise, does not necessarily constitute or imply its endorsement, recommendation, or favoring by the United States Government or the University of California. The views and opinions of authors expressed herein do not necessarily state or reflect those of the United States Government or the University of California, and shall not be used for advertising or product endorsement purposes.

This work was performed under the auspices of the U.S. Department of Energy by the University of California, Lawrence Livermore National Laboratory under Contract No. W-7405-Eng-48.

This report has been reproduced directly from the best available copy.

Available electronically at http://www.doc.gov/bridge

Available for a processing fee to U.S. Department of Energy

And its contractors in paper from

U.S. Department of Energy

Office of Scientific and Technical Information

P.O. Box 62

Oak Ridge, TN 37831-0062

Telephone: (865) 576-8401

Facsimile: (865) 576-5728

E-mail: reports@adonis.osti.gov

Available for the sale to the public from

U.S. Department of Commerce

National Technical Information Service

5285 Port Royal Road

Springfield, VA 22161

Telephone: (800) 553-6847

Facsimile: (703) 605-6900

E-mail: orders@ntis.fedworld.gov

Online ordering: http://www.ntis.gov/ordering.htm

\section{OR}

Lawrence Livermore National Laboratory

Technical Information Department's Digital Library

http://www.llnl.gov/tid/Library.html 


\section{EE FY00 Report:}

Nanostructure Multilayer Materials for Capacitors

Troy W. Barbee, Jr. L-350

Lawrence Livermore National Laboratory

Livermore CA 94550-9234

(925) 423-7796: fax; (925) 422-6892: e-mail; barbee2@ llnl.gov

\section{Objectives:}

- Apply Reactive Magnetron Sputter Deposition to the Fabrication of High Energy Density Capacitors for Electrical Power Control Applications

- Develop Low Loss - High Breakdown Field Moderate $(10<k<50)$ to High $(50<k<150)$ Dielectric Constant Materials

- Fabricate Demonstration Capacitors Having Application Defined Specifications

- Technology Transfer Capacitor Fabrication Process to Industry

\section{Approach:}

- Develop High Energy Density Capacitor Performance By Achieving High Breakdown Fields

- Develop Low Loss - High Breakdown Field Moderate $(10<k<50)$ to High $(50<k<150)$ Dielectric Constant Materials

\section{Accomplishments:}

- $\quad$ Extended Magnetron Sputter Deposition Fabrication of High Energy Density - High Breakdown Field Capacitor Structures to Dielectric Materials with $3<\mathrm{k}<50$. 
- Developed a Qualitative Explanation for the Systematics in the Breakdown Field Dependence on Dielectric Constant.

- Increased the Yield of the Reactive Magnetron Sputter process for Fabrication of High Energy Density Capacitors: $\left(<0.03\right.$ Defects $\left./ \mathrm{cm}^{2}\right)$

- Developing Technology Transfer Relations with Capacitor Manufacturers

\section{Future Directions:}

- Continue Development of High Breakdown Strength - Low Loss - Low Temperature Dependence Dielectric Materials to Increase the Performance of Multilayer Material Capacitors.

\section{Introduction:}

Only two intrinsic approaches to increasing the density of energy stored in capacitors are known:

1) Increase the Dielectric Constant while maintaining the breakdown filed.

2) Increase the breakdown field for a given dielectric constant material

The maximum energy density, $\mathrm{E}_{0}$ (Joules $/ \mathrm{cm}^{3}$ ) that can be stored in the dielectric of a capacitor is given by:

$$
\mathrm{E}_{0}=1 / 2 \mathrm{k} \varepsilon_{0} \mathrm{~V}_{\mathrm{b}}^{2} \text { (Joules } / \mathrm{cm}^{3} \text { dielectric) }
$$

Where $k$ is the relative permittivity (dielectric constant), $\varepsilon_{0}$ is the permittivity of free space $\left(8.894 \times 10^{-14} \mathrm{~F} / \mathrm{cm}\right)$ and $V_{b}$ the dielectric material breakdown field. In this project we have successfully developed capacitor structures using dielectric materials with $3<\mathrm{k}<$ 50 that exhibit high breakdown fields. The observed performance of these capacitors as characterized by the energy stored per unit 
volume of dielectric at $\mathrm{V}_{\mathrm{b}}$ are compared on the basis the breakdown field in Figure 1.

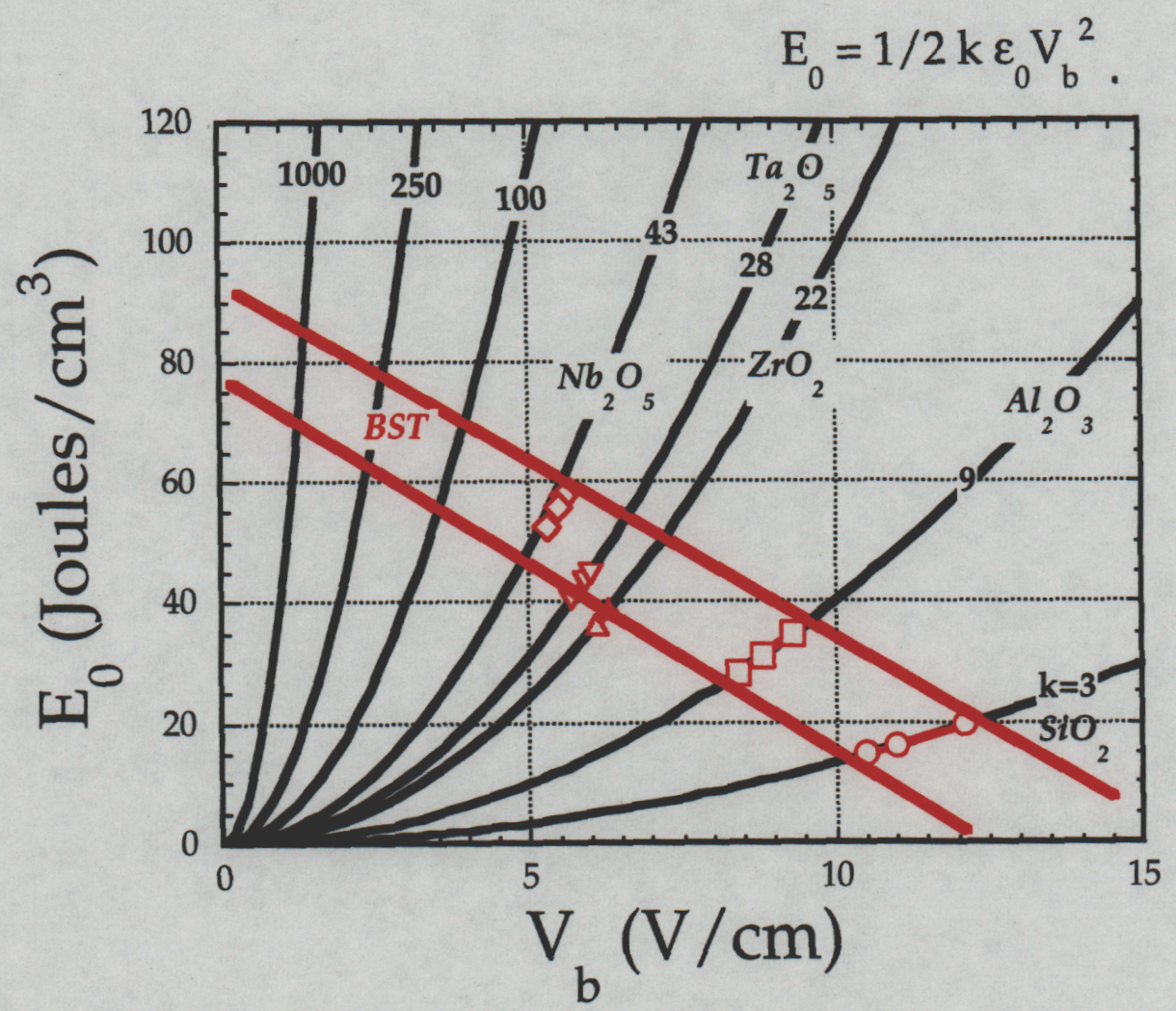

Figure 1. The experimentally observed performance of $\mathrm{SiO}_{2}, \mathrm{Al}_{2} \mathrm{O}_{3}$, $\mathrm{ZrO}_{2}, \mathrm{Ta}_{2} \mathrm{O}_{5}, \mathrm{Nb}_{2} \mathrm{O}_{5}$ and single crystal $B S T$ (HP data) dielectric capacitors characterized by the energy stored per unit volume of dielectric at $V_{b}$ are compared on the basis the breakdown field. The energy stored per unit volume of dielectric calculated for $k=3,9,22$, $28,43,100,250$ and 1000 is also plotted for comparison.

It is surprisingly clear from the results presented in Figure 1 that there is a systematic dependence of $E_{0}$, the stored energy density, and the breakdown field on the dielectric constants of the materials studied. These data show that the more polarizable the dielectric (increasing $\mathrm{k}$ ), the lower the breakdown field. This is delineated in Figure 1 by the band between the two straight lines bounding our experimental results. When extrapolated to high $\mathrm{k}$ materials our data, coupled with the HP single crystal BST result, indicates that there 
may be an upper limit to the stored energy density achievable in the dielectric of a capacitor -80 to 100 Joules $/ \mathrm{cm}^{3}$.

There are several physical effects that may provide mechanistic rationale for these two observations. First, at an applied macroscopic field of $10 \mathrm{MV} / \mathrm{cm}$ the average field at the atomic level is $0.1 \mathrm{~V} / \AA$, the threshold for field driven chemical reactions that may initiate breakdown. Second, in the case of dielectrics the local electron and ion displacements resulting from such an applied potential are directly related to the stored energy density and may be very large. Thus, electro-striction generated stresses can be significant and initiate failure or breakdown by mechanical means. Also, the displacement of electrons may result in local transport and "hot electron injection" again leading to breakdown. Third, stored energies at levels greater than 50 joules $/ \mathrm{cm}^{3}$ are a significant fraction of the energy differences ( 150 to 400 joules $/ \mathrm{cm}^{3}$ ) between the polymorphic atomic arrangements of many dielectric materials. If a local phase transformation is initiated as a result of the electrostriction strains or is initiated as a process decreasing the stored energy by changing the properties of the dielectric it is likely that breakdown would be initiated. Although these mechanisms are only qualitatively outlined here understanding their impact is worth attempting.

The most significant result is the upper limit in stored energy indicated for very high dielectric constant materials: $\mathrm{E}_{0} \leq 80$ to 100 joules $/ \mathrm{cm}^{3}$. If a materials dielectric constant is 1000 or larger its breakdown field at this stored energy level is expected to be less than one million volts per centimeter; $\mathrm{V}_{\mathrm{b}}<1.0 \mathrm{MV} / \mathrm{cm}$, a conclusion consistent with experience in this field. Although it is in principle possible to achieve the highest stored energy per unit volume of dielectric in a capacitor by using the highest dielectric constant materials the complexity of these materials makes this result difficult to achieve, if not obtainable.

Future efforts will be focussed on the application of dielectric materials having permittivities in the range of 50 to 250 . The upper limit of $k>250$ is chosen as materials having higher values of $k$ are typically non linear in response, exhibit a significant temperature dependence of $k$ and are chemically complex. 